\title{
Conflictos territoriales en la comunidad indígena de Sikilta. Territorio: Mayangna Sauni Bas. Municipio de Siuna, RAAN. Período 2007.'
}

Hedley Lucio Díaz Gutiérrez²

Leonor Ruiz Calderón ${ }^{3}$

\section{Resumen}

La presente investigación fue efectuada en el territorio: Mayangna Sauni Bas [número tres], enfocada hacia el conflicto entre la comunidad indígena de Sikilta y las comunidades de Kupahwas, Lawas y Toro Waslalita que se ubican dentro de la reserva de biósfera de BOSAWAS. Considerando que este trabajo alertará a las autoridades municipales, regionales y nacionales sobre la urgencia de ponerle fin a esta problemática.

El objetivo central fue analizar los conflictos que se han ocasionado dentro de este territorio, sus causas y consecuencias, el marco jurídico sobre la tierra, territorio y valorar el papel que han jugado las instituciones gubernamentales y no gubernamentales en este problema. Esta investigación es cualitativa con un enfoque etnográfico, utilizando las principales prácticas antropológicas: observación participativa, entrevistas formales e informales y grupo focal con las autoridades. Las conversaciones con los miembros de la comunidad de Sikilta y de comunidades vecinas, permitieron verificar la información oral. Para las entrevistas con los colonos mestizos se empleó el idioma español y para la comunidad de Sikilta, se utilizó la lengua sumu- mayangna.

Entre los principales hallazgos se encuentra: el desplazamiento de familias mestizas ubicadas en el Occidente y Norte de Nicaragua en busca de una tierra fértil, y que solamente los pueblos indígenas poseen, mientras la zona de los colonos es un desierto degradado sin producción, generando en una de las causa de los conflictos por tierra. Consecuencia de ello es el peligro de extinción de la cosmovisión de los pueblos indígenas, su cultura y su administración que ancestralmente han conservado y protegido. Los suelos están degradados, los ríos han bajado su nivel que ancestralmente han mantenido. Para la actividad de la caza los comunitarios cada vez se alejan hacia las profundidades del bosque para poder obtener carne de animales silvestres. Los indígenas de Sikilta conocen las leyes y normas que rigen la administración de los recursos naturales; sin embargo, no han podido resolver el conflicto. Las organizaciones

\footnotetext{
1 Monografía realizado con el financiamiento del proyecto PATHWAY II Support to Graduation Research Projects of Indigenous and Afro Descendant Students in URACCAN, de la Fundación FORD.

2 Lic. En Sociología del Recinto URACCAN, Recinto Las Minas.

3 MSc. en Antropología Social, URACCAN, Recinto Las Minas, RAAN. Tutora de la investigación.
} 
gubernamentales y no gubernamentales que están relacionadas al tema, no han trascendido en ayuda a los comunitarios de Sikilta para resolver sus problemas. Se considera que no ha existido voluntad de las autoridades regionales y municipales para ponerle fin al conflicto.

Palabras claves: conflicto, territorio, demarcación, comunidades indígenas, reserva, organización, colonos, indígenas, mestizos, derecho.

\section{Introducción}

En la historia de los pueblos indígenas, la defensa y la recuperación del territorio ha constituido el corazón y el motor de consolidación de los diferentes procesos organizativos. En este caminar se encuentra la defensa de los resguardos, la oposición al pago del terraje, la recuperación del territorio. Por esa razón, actualmente continúa lo que algunos pueblos indígenas han llamado "La liberación de la Madre Tierra", con la seguridad de que la fuerza organizativa es la primera herramienta para que sean devueltos y reconocidos los derechos de los pueblos indígenas. Sin embargo, para éstos ha sido claro que el no indígena también tiene sus armas, una de ellas, la ley, que no es precisamente la ley natural, sino la ley del hombre, que hace y se deshace, generalmente a favor del poderoso y en contra de los derechos indígenas. Pero en la historia del movimiento indígena hay ejemplos claros de cómo la audacia y la fortaleza indígena han podido intervenir en desviar los efectos nocivos de las leyes del Estado. Las tierras desde la filosofía de las comunidades es la madre, dadora de vida, es la base de existencia como pueblo. Jorge Jenski M., la define así: "La tierra para los miskitus además de medio de producción y fuente de bienes materiales, es un elemento indisoluble de la cultura y del sistema de valores indígena" (1986, p 302).

En la presente investigación se abordaron los conflictos del territorio Mayangna Sauni Bas, desde la visión del derecho positivo y a su vez consuetudinario o derechos colectivos que protegen a los pueblos indígenas y que están en el marco jurídico de la Autonomía de la Costa Caribe nicaragüense. Se pretende este estudio como un aporte al reconocimiento de los derechos colectivos de los pueblos indígenas y afrodescendientes.

La situación de demarcación territorial en las Regiones Autónomas se ha constituido como muy conflictiva entre las comunidades indígenas que se encuentra con o sin títulos y que reclaman demarcar y/o titular sus tierras. La inexistencia de límites claros entre comunidades, tal es el caso de comunidades con títulos reales, cuya población ha transgredido los límites originalmente señalados por el tratado Harrison - Altamirano, y que ocupan nuevos territorios que afectan otras comunidades. Comunidades sin 


\section{TERRITORIALIDAD}

títulos que no tienen delimitadas sus fronteras. Comunidades indígenas que tienen fronteras con nuevos vecinos mestizos llegados en años anteriores y comunidades nuevas (Rivera 1996, p. 114).

Los derechos consignados en las leyes del país han constituido un proceso de lucha constante de los pueblos indígenas ya que a través del tiempo, producto del mismo aislamiento estatal, éstos han empleado normas jurídicas posibilitando sanciones y obligaciones, creando sus propias reglas de convivencia. En esta situación las comunidades son una representación en un proceso estructurado con el tiempo y que se ha adptado a los cambios a los cuales han sido sometidas.

La importancia social del crecimiento de la protección del medio ambiente y los recursos naturales, aumentan también los conflictos ambientales en la agenda de problemas de las sociedades modernas. Además, las causas de los conflictos son de diferente naturaleza, en los países en desarrollo donde existe una estrecha correspondencia entre las condiciones de vida de las personas y estado de los recursos naturales, las consecuencias del uso de estos últimos tiene una relación inmediata con la población afectada.

Los pueblos indígenas tienen sus formas propias para normar el uso de los recursos naturales, en especial la tierra, las normas de derecho comunitario deben expresar autonomía en el sentido de derechos históricos a la tierra madre, al bosque, al mar, que deben estar congruentes con la legislación nacional respecto a la tierra. A partir del derecho consuetudinario se pretende explicar cómo las comunidades indígenas, a través de sus normas han establecidos criterios de uso y distribución de la tierra que no han sido tomadas en cuenta por el Estado nicaragüense. Pueblos indígenas que a partir de sus propias tradiciones y costumbres han establecidos sus propias normas en cuanto al uso de los recursos que se encuentran en su territorio. Los hombres y mujeres indígenas que habitan en este territorio, muestran preocupación en cuanto a la afectación de los recursos naturales e invasión al territorio, los cuales han estado esperando que las autoridades competentes se interesen en el asunto al igual la Comisión Nacional de Demarcación Territorial (CONADETI).

Las leyes en materia de los derechos indígenas se han utilizado de manera embustera con un sentido de discriminación hacia este grupo. A tal grado que el Gobierno Municipal, Regional y Nacional, no han demostrado voluntad en la aplicación de las mismas. Los resultados expuestos son de utilidad beligerante para las autoridades territoriales, los que están buscando estrategias que conlleven a la solución pronta de esta problemática, a que las autoridades regionales y comunales tomen al fin conciencia y voluntad de buscar soluciones al problema planteado. Las preguntas de 
investigación que guiaron este trabajo son: ¿Cuáles son las causas que han originado los conflictos por tierra en el territorio: Mayagna Sauni Bas [Territorio tres], ¿Cuáles han sido las consecuencias que han provocado estos conflictos? Y ¿cuál es el grado de conocimiento que el campesinado mestizo tiene en relación al régimen de propiedad comunal de los pueblos indígenas?

\section{Revisión de literatura}

Stavenhagen, refiere que la tierra es fundamentalmente un espacio físico de ocupación directa por parte de una unidad doméstica (familia) o una comunidad indígena, y al mismo tiempo constituye un factor de producción y subsistencia, un elemento indispensable para la supervivencia del grupo social. De acuerdo a las condiciones ecológicas, el nivel tecnológico y la organización de la producción, los distintos grupos indígenas requieren de extensiones variables de tierra para subsanar sus necesidades básicas (Stavenhagen, 2001, S/P).

\section{Cosmovisión indígena}

En el territorio mayangna se centran en la legalización de sus tierras, es el valor de la tierra que aprecia la cultura dominante. La cosmovisión, sobre el concepto de la tierra no es la economía, no es la acumulación de capital, sino que es un valor cultural, la relación para el hombre con la naturaleza es muy estrecha dado que el hombre indígena mayangna no puede vivir sin ella, ni la naturaleza sin el hombre indígena; por lo que existe una interacción permanente (Salgado y Duarte, 2002, p. 15).

\section{Los territorios indígenas}

El territorio indígena es el espacio geográfico-cultural que los pueblos indígenas reclaman como un derecho colectivo, indispensable para su sobrevivencia, identidad y reproducción como pueblos. Mientras que la tierra es reclamada como una necesidad económica y social, el territorio lo es como una necesidad cultural y política, vinculada al derecho de autonomía y de libre determinación. La destrucción y negación de los territorios indígenas constituye una forma más de etnocidio, y por lo tanto una seria violación de los derechos humanos de los pueblos indígenas (Stavenhagen, loc.cit).

\section{Formas originarias de adquisición de la propiedad comunitaria.}

A la llegada de los españoles, la propiedad sobre la tierra era ejercida de manera colectiva, es decir era propiedad comunal. Este tipo de propiedad se originaba antes de la 'Conquista Española' y aunque es formalizada con la implementación de las Leyes 
de India promulgada por la Corona Española; su origen anterior se sustenta tanto desde el punto de vista del Derecho Indígena, como del Derecho Clásico. Esta forma de propiedad es la más antigua de Nicaragua y desde el punto de vista del Derecho Clásico encontramos su origen antes de la 'Conquista Española' y la adquirieron los Pueblos Indígenas. La ocupación es un modo de adquirir una cosa no perteneciente a nadie, por la toma de posesión de ella, efectuada con intención de convertirse en propietario (Pinaol y Ripert, 1997, p. 48).

Conflicto es un proceso interaccional que como tal nace, crece, se desarrolla y puede a veces transformarse, desaparecer y otras veces permanecer estacionario; se construye recíprocamente entre dos o más personas, entendiendo por partes a personas, grupos grandes o pequeños, en cualquier combinación (Pasos, 2004, P.7).

\section{Causas y consecuencias de los conflictos territoriales}

Las profundas desigualdades económicas entre indígenas y no-indígenas, la marginación social de aquellos, su exclusión política y subordinación cultural, conforman un cuadro histórico de discriminación persistente que no puede calificarse más que de racismo estructural, es decir, enraizado en las estructuras de poder y de dominio que han revelado: caracterizando a las sociedades latinoamericanas durante siglos. De allí que aún hoy en día, con políticas desarrollistas y discursos incluyentes, la situación de los pueblos indígenas en el contexto nacional no se ha modificado sustancialmente. No obstante, se han dado cambios y se están generando dinámicas que permiten vislumbrar nuevas posibilidades en la centenaria relación entre pueblos indígenas y Estados Nacionales (Ibíd.).

Aproximadamente diez mil hectáreas de bosque fueron sujetas a quemas severas en la Costa Atlántica desde la estación seca de 1990, en parte producto del fin del conflicto bélico y el reasentamiento de repatriados en las zonas rurales que practica la agricultura tradicional (Blandford, 2002, p. 65). Continúa señalando el autor que la frontera agrícola es el producto de una serie de factores que tienen su origen en la economía desarrollista que fue aplicándose en el país desde la década de los años 1930 y que expulsó a miles de pobladores de las planicies fértiles del Pacífico hacia la Región Central y Atlántico del país, estas podrían considerarse causas a nivel micro, como es la de afinidad de casi la totalidad de campesinos de frontera agrícola a la ganadería extensiva por ser esta actualmente una de las más rápidas y seguras alternativas económicas del país. 


\section{Marco jurídico sobre territorialidad y tierras indígenas y sus implicancias en el conflicto territorial}

Los pueblos indígenas definen su derecho a la autodeterminación como principal derecho humano colectivo. En esto no existe modelos homogéneos, sino que cada pueblo indígena y cada país tiene sus propias expresiones y prácticas de autodeterminación indígena, existe tratados, leyes especiales, reglamentaciones y acuerdos sobre Autonomías locales, comunales, municipales, comarcales o regionales, las cuales abren espacios para la creación y el desarrollo de instituciones propias y regulan las relaciones entre los pueblos indígenas y los gobiernos nacionales. Este proceso se desarrolla paralelamente al reconocimiento internacional de derechos indígenas y la propiedad colectiva indígena sobre sus territorios y los recursos naturales (Stavenhagen, loc. cit).

En el Pacto Internacional de Derechos Civiles y Políticos (1966), establece en el artículo 1 que: "Todos los pueblos tienen el derecho de libre determinación. En virtud de este derecho establecen libremente su condición política y proveen asimismo a su desarrollo económico, social y cultural. El artículo 27 establece: "En los Estados en que existan minorías étnicas, religiosas o lingüísticas, no se negará a las personas que pertenezcan a dichas minorías el derecho que les corresponde, en común con los demás miembros de su grupo, a tener su propia vida cultural, a profesar y practicar su propia religión y emplear su propio idioma" (Sánchez, 1996).

La Ley de Autonomía que se implementa a partir de la lucha de los pueblos indígenas en los años ochenta, se establece como un régimen especial para las comunidades étnicas y pueblos indígenas que habitan la Costa Atlántica de Nicaragua. Recoge la necesidad que tienen las comunidades a un reconocimiento histórico sobre la tierra, en el capítulo IV, artículo 36, la Ley de Autonomía o ley número 28 dice: "La propiedad comunal la constituyen las tierras, aguas y bosques que han pertenecido tradicionalmente a las comunidades indígenas de la Costa Atlántica." (Ley 28-1987). Antes bien, estos derechos consignados en las leyes del país existen como un proceso de lucha constante de los pueblos indígenas ya que a través del tiempo, producto del mismo aislamiento estatal, éstos han empleado normas jurídicas posibilitando sanciones y obligaciones, creando sus propias reglas de convivencia. En esta situación las comunidades son una representación que se ha estructurado con el tiempo y adaptándose a los cambios que han sido sometidas. 


\section{Convenio 169 de la OIT y la propiedad comunitaria}

El Convenio 169 constituye el instrumento jurídico internacional más completo que en materia de protección a los derechos de los pueblos indígenas y tribales se haya adoptado hasta la fecha. En relación al Derecho de Propiedad de los Pueblos Indígenas, este establece conceptos muy novedosos que son a la vez fuente del Derecho Moderno (Silva, 1998, p. 201).

\section{Ley de delitos ambientales contra el medio ambiente y los recursos naturales. Ley 559}

Desde mediados del siglo XIX se desarrolló en toda la Costa Atlántica un sistema económico basado en la extracción de materia prima de la abundancia de recursos existentes en la Costa Atlántica (caoba, cedro real, banano, hule, chicle, minerales, etc.); como ya se ha visto, estas actividades eran llevadas a cabo en su mayoría por empresas norteamericanas que lograron extraer gran cantidad de recursos al punto que la cantidad debajo de ser rentable las compañías cerraban y se marchaban dejando a la población nativa dependiendo nuevamente de sus formas tradicionales de vida pero con menos recursos y problemas ambientales más severos. (Bradford, 2002, p. 63).

\section{El derecho consuetudinario}

Diversos autores y diferentes corrientes en Ciencias Sociales han definido de distintas maneras el derecho consuetudinario que conceptualizan las leyes por costumbres en las comunidades indígenas. Entre ellas: normas generales del comportamiento público, orden interno, reglamentación sobre el acceso y la distribución de los recursos escasos, que entre otras cosas definen al derecho en las sociedades indígenas. Bronislau Malinowski desde la Antropología funcionalista clásica habla de las normas y/o leyes por costumbre, cuando dice que: "las costumbres en esas sociedades deberían considerarse como normas jurídicas que se caracterizan por su carácter obligatorio y vinculante..." (1982:54). Permite entrever que las comunidades indígenas por ser una "sociedad salvaje" tienen normas de convivencia. Haciéndolos pasar como un pueblo de convivencia armoniosa y sin conflictos internos. Malinowski estudió una sociedad aislada, buscando una sociedad pura, donde las normas sociales no habían sido alteradas. En su estudio pretende demostrar cómo opera en esa sociedad "salvaje", la cultura en cuanto a la violación de las normas y los mecanismos de 'restitución del bien dañado por esa violación'.

El sistema consuetudinario de estos pueblos incluye, entre otros, las formas de tenencia colectiva de la tierra, la organización interna del liderazgo tradicional comunal como 
son los Consejos de Ancianos, las Juntas Directivas Comunales, los Síndicos, los Jueces Comunales, etc. Quienes se encargan de preservar el equilibrio social comunal mediante el respeto a las costumbres y tradiciones del grupo social; de los asuntos referentes a la tenencia y administración de los recursos naturales y la tierra de la Comunidad; el cometido de faltas entre los miembros de la Comunidad y agresiones provenientes de fuera del grupo social; son algunos de los asuntos de los que se encargan las autoridades comunales. No obstante, el derecho consuetudinario de las comunidades indígenas de la Costa Atlántica de Nicaragua no ha sido estudiado lo suficiente y existe mucho desconocimiento por parte del Estado al respecto (López B. s/f).

\section{Los Pueblos Indígenas en la Ley de Reforma Agraria}

El artículo107 de la Constitución Política de Nicaragua establece: "La reforma agraria eliminará cualquier forma de explotación a los campesinos, a las comunidades indígenas del país y promoverá las formas de propiedad compatibles con los objetivos económicos y sociales de la nación establecidos en esta Constitución. El régimen de propiedad de las tierras de las comunidades indígenas se regulará de acuerdo a la ley de la materia" (Constitución de la República, 2003).

\section{Las instituciones Gubernamentales y no Gubernamentales en los conflictos territoriales}

Para la dirigencia indígena, el Estado nicaragüense ha generado un reducido número de concesiones en aspectos poco significativos en las estructuras económicas, sociales, culturales y políticas, de tal manera que no existe una transformación integral de la sociedad y Estado monoétnico, discriminador y racista. Así mismo, perciben a las principales fuerzas políticas, de izquierda o derecha, como oportunistas y utilitarias respecto a los intereses y demandas indígenas y en algunos casos como francamente opuestas al reconocimiento y cumplimiento de dichas demandas (URACCAN 2001, $\mathrm{s} / \mathrm{p})$.

Perciben al Estado como una realidad con la que desafortunadamente hay que contar, sobre todo para resolver las demandas materiales sectoriales y están conscientes de las grandes dificultades de plantear demandas "transformativas" del aparato de Estado. A pesar de la diversidad de intereses entre las organizaciones indígenas y étnicas, ha existido un esfuerzo concertado por mantener los elementos centrales de la institucionalidad autonómica y de hacer avanzar exitosamente dos instrumentos legales que definen las relaciones entre el Estado nicaragüense y los pueblos indígenas 
en los últimos diez años, a saber: la Ley de Autonomía No. 28 y la ley No. 445 sobre tierras indígenas (Gurdián y Kauffmann, 2005 p. 10).

\section{Gobierno municipal}

La Ley de Municipio de 1987, es el principal fundamento legal para la participación ciudadana en la gestión ambiental y es el marco de referencia obligatorio para cualquier otra Ley sobre la materia. El Municipio es considerado como expresión del Estado en el territorio por medio de la gestión y prestación de servicios ejerce competencias sobre materias que afectan su desarrollo, preservación del medio ambiente y la satisfacción de las necesidades de sus pobladores (Ley de municipios, 1997, p. 38).

\section{Consejo Regional}

El Consejo Regional Autónomo del Atlántico Norte de acuerdo a sus competencias, tendrá la responsabilidad de promover los procedimientos de demarcación y titulación de las tierras comunales para la cual deberá coordinarse con el Gobierno Central. En el proceso de negociación las comunidades estarán representadas por sus autoridades tradicionales las que serán asistidas por asesores técnicos elegidos por ellas mismas, en cada uno de estos procedimientos y con el fin de ofrecer una mayor protección a los recursos naturales, el Gobierno Central tendrá participación directa para favorecer a las comunidades en sus negociaciones. En caso de que una de las partes no esté de acuerdo con la resolución podrá impugnarla ante la junta directiva del Consejo Regional para que pase la solicitud al plenario, el que deberá resolver en la siguiente sesión por medio de una resolución definitiva. Si el presidente del Consejo Regional no respondiere en el término señalado o no diera lugar a la impugnación, el interesado podrá solicitar por escrito al secretario del Consejo Regional que el caso sea discutido en el pleno del Consejo Regional. La resolución del Consejo agota la vía administrativa (ley 445, 2003).

\section{Materiales y métodos}

El estudio se ubica en el territorio Mayagna Sauni Bas [número tres]. Un 90.6\% de este territorio se encuentra dentro del área protegida de biósfera de BOSAWAS (nombre compuesto por los nombres de los accidentes geográficos que marcan sus límites: Bocay, Saslaya y Waspuk). Es de carácter cualitativo con enfoque etnográfico y de corte transversal. 
La población en estudio fueron las personas habitantes del territorio Mayangna Sauni Bas, que conforman nueve comunidades: Kupahwas, Lawas, Kulta, Toro-Uly, Wamalu, Casas Viejas, Toro-Waslalita, Waslalita y la comunidad mayangna de Sikilta que comprenden 1,391 habitantes. Este estudio se realizó utilizando las principales prácticas antropológicas: observación participativa, entrevistas formales e informales y grupo focal con las autoridades. Las conversaciones con los miembros de la comunidad de Sikilta y de comunidades vecinas, independientes y por separado, permitieron verificar la información oral recibida. Para las entrevistas con los colonos mestizos se usó el idioma español y para la comunidad de Sikilta, se utilizó la lengua sumu- mayangna y luego se tradujo al español.

\section{Resultados y discusión}

\section{Causas y consecuencias de los conflictos territoriales}

Los comunitarios mayangnas de Sikilta, expresaron que el conflicto por ocupación de una parte de su territorio es viejo, siendo en el año de 1990 el primer desalojo. Los terceros que actualmente están ocupando el territorio son de la tercera generación, es decir, que los primeros vendieron a los segundos y estos a la actual generación. Los ancianos de la comunidad contaron que cuando la comunidad de Sikilta huyó hacia Honduras por problemas de la guerra durante el año 1985, los mestizos aprovecharon esta situación e invadieron las tierras comunales. A partir de esta época ha sido difícil controlar esta situación, en la que cada año aumenta la cantidad de familias que se asientan en el territorio. A pesar de la protección legal aparentemente asegurada mediante título de reforma agraria que posee la comunidad de Sikilta, en la práctica se hizo evidente que su imprecisión en la definición de límites permitió a algunos colonos mestizos invadieran sus tierras. Esta situación se fue agravando al paso de los años, haciéndose insostenible a partir de 1994. Otra dificultad, en el plano legal, fue provocada por un error del propio Ministerio de Reforma Agraria-MIDINRA-, el cual en 1984 otorgó títulos a algunos colonos mestizos sobre parcelas ubicadas dentro del territorio de la comunidad de Sikilta.

Cada año aumenta la cantidad de familias que se asientan en el territorio en estudio. Con referencia al año de 1994, el número de familias invasoras aumentó siete veces en proporción. El mayor incremento se dio entre el año de 1997 al 2005, registrándose en un $14 \%$. Entre las consecuencias que ha traído este conflicto se puede mencionar el aumento de áreas deforestadas, introducción de ganadera extensiva, la práctica de agricultura migratoria, contaminación y disminución de los caudales hídricos por el despale indiscriminado y uso de agroquímicos. Los colonos mestizos han convertido 


\section{TERRITORIALIDAD}

las tierras de vocación forestal a ganaderas, ya que la principal actividad económica es la práctica ganadera en la que va en vía de expansión en estos sectores. La mayor parte de las familias, tienen grandes cantidades de pastizales para alquilar o con aspiraciones ganaderas, por lo que están tumbando bosques primarios. Esta transformación de bosques vírgenes a pastoriles a causa de la frontera agrícola, consiste en cultivar granos básicos para luego vender las tierras con mejoras a campesinos - ganaderos. Posteriormente los agricultores pobres se trasladan montaña adentro para seguir teniendo acceso a tierras vírgenes, afectando además los ojos de agua.

El señor Amado Gómez Mairena, comunitario de Lawas manifestó: "nos venimos para acá por la guerra, allá no se soportó, no hubo descanso. Aquí sí, aquí no hubo muchas cosas, aquí hay un poco mejor de vivir en el hogar" (Entrevista comunidad de Lawas, 12 de Abril 2008). Lo anterior mencionado por el entrevistado, deja claro que uno de los factores que incidió para que ocuparan este territorio fue la guerra de los 80 y además que no tenían tierras para trabajar.

Los incendios forestales tienen un efecto sumamente dañino sobre el bosque, ya que aparte de quemar grandes extensiones degradan la biodiversidad tanto animal como vegetal, se afecta directamente el banco de semillas en el suelo del bosque evitando el emplazamiento directo de las especies existentes en el mismo. Esto último tiene como consecuencia el cambio de la composición de las comunidades forestales, que tienden a ser sustituidas por gramíneas y otros tipos de malezas. Así mismo la parte física del suelo es afectada por las altas temperaturas que hacen el suelo más compacto y quebradizo, lo cual retarda la sucesión hacia el bosque original, por otro lado un suelo desprovisto de vegetación luego de la quema es erosionado fácilmente por la lluvia, perdiéndose así valiosos nutrientes que toman mucho tiempo en recobrarse.

Todo estos resultados coinciden con lo que Stavenhagen (2001) refiere, que los agricultores con prácticas de roza y quema practican la agricultura intensiva, necesitan grandes extensiones de tierra para sus prácticas, utilizando agroquímicos, mientras que el indígena no maneja a su antojo la tierra, sino que ven en ella un bien colectivo y comunal bajo normas sociales y culturales. Esta ambigüedad es la que ha creado situación de tensión, cuando los colonos mestizos desconocen o no quieren reconocer las normas culturales de los pueblos indígenas en relación al uso de la tierra.

Se pudo constatar que en las áreas deforestadas corresponden a los cultivos de granos básicos, pastizales, tacotales, musáceas y tubérculos. De acuerdo a los datos obtenidos y lo observado, indican que los sectores: Kupawas, el Toro Waslalita y Uly El Toro, es donde se están implantando la mayor cantidad de pastizales. Todo lo anterior concuerda con Bladford (2002), afirmando que en la Costa Atlántica de Nicaragua, 
aproximadamente diez mil hectáreas de bosque han sido sujetas a quemas por agricultores que practican la agricultura tradicional. El mismo autor refiere que estos campesinos practican más la ganadería extensiva por ser una de las más rápidas y seguras alternativas económicas del país. Los ganaderos autóctonos en la Costa Atlántica responden al mercado local con una población demandante de carne y leche mucho menor. Esto hace que la actividad ganadera de frontera agrícola sea más destructora del bosque que la ganadería. Una de las consecuencias mayores no sólo es la pérdida de la diversidad biológica del territorio, sino también la diversidad cultural y el conocimiento milenario que sobre los recursos naturales poseen los pueblos indígenas. Las tierras han perdido su valor agrícola que ha sido sustituido por el valor agropecuario. Otro aspecto creado es la inestabilidad de inseguridad ciudadana, por las dos partes en conflicto, los colonos se sienten amenazados a ser desalojados en cualquier momento y por otro lado, los mayangnas se sienten inseguros ante la prepotencia y arrogancia de algunos colonos cuando pasan por su territorio con cantidades de ganado, perros y armas, creando un clima de amenaza e inseguridad.

Esto lo reafirma Pasos (2004), explicando que las desigualdades económicas, sociales, culturales y políticas entre indígenas y no-indígenas, conforman un cuadro histórico de discriminación persistente que se denomina racismo estructural, enraizado en las estructuras de poder y de dominio que han venido caracterizando a las sociedades latinoamericanas durante siglos. Todo este problema les ha traído serias dificultades a todas las familias asentadas en esta comunidad y en especial a las mujeres de la comunidad, quienes tienen que viajar un poco más largo para encontrar y acarrear agua para el consumo y preparación de los alimentos.

\section{El marco jurídico sobre territorialidad y tierras indígenas y sus implicancias en el conflicto territorial}

El pueblo indígena del territorio Mayangna Sauni Bas [número tres] poseen conocimientos del marco jurídico sobre las tierras indígenas, entre las que manejan en primera instancia está la constitución de la República de Nicaragua, el estatuto de la Ley de Autonomía (Ley 28) y la Ley sobre Demarcación Territorial (Ley 445). En materia internacional conocen el Convenio 169. Manejan el término de territorio como un todo, de manera que no se involucra toda la comunidad. Mientras los mestizos colonos no conocen el de territorio, sólo el concepto de tierra. Lo que armoniza con lo que Stavenhagen refiere a cerca del concepto de territorio y tierra que tienen los indígenas, en la que dice que el concepto de territorio es más amplio que el de tierra.

Cuando se habla de territorio, se refiere al espacio geográfico en el cual se desenvuelve la dinámica de las sociedades indígenas, en la que está vinculada la cultura, la historia 
y la identidad de un grupo indígena dado, es el espacio que reclaman como un derecho colectivo, mientras que la tierra es reclamada como una necesidad económica y social, el territorio lo es una necesidad cultural y política, vinculado al derecho de autonomía y de libre determinación. La destrucción y negación de los territorios indígenas constituye una forma más de etnocidio, y por lo tanto una seria violación de los derechos humanos de los pueblos indígenas. Para el pueblo indígena de Sikilta, la tierra no es una propiedad individual y privada a ser manejada al antojo de su dueño. Según su tradición, ven en la tierra un bien colectivo y comunal que puede ser usufructuado temporalmente para lograr la subsistencia, pero en el marco de determinadas normas sociales y culturales y con estricto apego al bien de la colectividad. Así, las tierras indígenas se dividen generalmente en áreas propiamente comunales (con acceso libre para los miembros de la comunidad), y áreas parceladas de las que puede disponer de acuerdo con los usos y las costumbres del grupo la unidad doméstica o familia, sin que ello signifique dominio o propiedad plena en el sentido que le da la legislación nacional a la propiedad privada. Esta aparente ambigüedad ha creado situaciones de tensión.

Al preguntarles cómo obtuvieron conocimientos acerca del marco jurídico, expresaron que han sido capacitados por organismos no gubernamentales como la Organización de Estados Americanos (OEA), en temas de apropiación del derecho consuetudinario que significa sucesos que ocurren en la Comunidad culturalmente. El Instituto para la Democracia (IPADE), ha sido otro organismo que les ha brindado capacitación sobre participación ciudadana y el Ministerio de Recursos Naturales (MARENA) sobre cómo conservar y proteger el bosque. (Entrevista con Celestino Taylor, Sikilta-Siuna, 2007).

Los conocimientos de los comunitarios sobre la apropiación de estas leyes es aplicado a nivel territorial, municipal y nacional, los pobladores de la comunidad mayangna de Sikilta practican sus propias leyes que manejan desde la antigüedad, reconocido como el derecho consuetudinario consistente en costumbres y tradiciones en asuntos referentes a la tenencia y administración de los recursos naturales, faltas y agresiones entre los miembros de la comunidad y fuera del grupo social. A partir del derecho consuetudinario se pretende explicar cómo las comunidades indígenas a través de sus normas han establecido criterios de uso y distribución de la tierra que no han sido tomadas en cuenta por el Estado nicaragüense. Que a partir de sus propias tradiciones y costumbres han establecidos sus propias normas en cuanto al uso de los recursos que se encuentran en su territorio. 
Al respecto, un guardabosque oficial expresó:

"Antes no habían los colonos invasores al territorio de Sikilta, así queremos vivir en la actualidad a través de nuestro consuetudinario. Además en este año 2007, plantean que nos reconocen a nuestro derecho como pueblos indígenas de Nicaragua, los primeros planteamientos que tenemos como pueblos que necesitamos saneamientos y el segundo es el desalojo de los colonos invasores del territorio indígena Mayangna Sauni- Bas, después de que se creó Ley 445, todavía no genera el contenido de esa Ley, sólo cuatro veces diagnosticaron, de allí se le dijeron a los autoridades municipales ahora vamos a desalojar los colonos invasores que están en dentro del territorio indígena Mayangnas Sauni- Bas Sikilta". (Entrevista a Celestino Taylor, Sikilta, Siuna-RAAN, 2007).

Con el conocimiento en relación a la legalidad de sus tierras que tienen los comunitarios de Sikilta, han realizado acciones como el de regresar a colonos que se han internado en la comunidad con el afán de posicionarse. Caso específico lo que ocurrió en mayo del año pasado (2007). Los límites de su territorio están diseñados conforme algunos elementos naturales, ejemplo: el río, cerro, quebradas, estos límites se conocen de generación en generación transmitidos de forma oral por los ancianos. Es importante señalar que el concepto de territorio que tienen es más amplio que el de tierra. Se refiere al espacio geográfico en el cual se desenvuelve la dinámica de la comunidad indígena, y con el cual está vinculada su cultura, la historia y la identidad como mayangnas. El territorio indígena es el espacio geográfico-cultural que los pueblos indígenas reclaman como un derecho colectivo, indispensable para su sobrevivencia, su identidad y su reproducción como pueblos. Mientras que la tierra es reclamada como una necesidad económica y social, el territorio lo es como una necesidad cultural y política, vinculado al derecho de autonomía y de libre determinación. La destrucción y negación a su derecho que tienen de los territorios indígenas constituye una forma más de etnocidio, y por lo tanto una seria violación de los derechos humanos de los pueblos indígenas. Los nuevos instrumentos internacionales sobre derechos humanos de los indígenas hacen hincapié en la importancia de sus territorios, y en la legislación nacional y regional se reconocen estos derechos, aunque todavía cuesta mucho hacerlos efectivos.

El tiempo que tienen de habitar los colonos en las tierras aledañas, oscila entre los 10 y 15 años, generalmente estas personas llegaron a la zona en la década de los años 90 durante el desarme de todos los grupos armados que estaban incursionando en las montañas y durante esta época el gobierno otorgó tierras a estos grupos sin valorar y considerar que estas tierras eran propiedad de indígenas que habitan la zona desde hace varios siglos. La mayoría de las personas consultadas compran y venden entre 
$C \$ 500$ y $C \$ 2000.00$ la manzana de terreno o tierra a otros colonos invasores. Lo que coincide con López (s/f), refiriendo al derecho consuetudinario, que a pesar que existe en las comunidades indígenas, de la Costa Atlántica de Nicaragua, no ha sido estudiado lo suficiente y existe mucho desconocimiento por parte del Estado al respecto.

Es relevante mencionar que las mujeres indígenas al igual que los hombres no desconocen sus derechos, las leyes que los amparan; sin embargo, las mujeres no tienen ninguna participación en este debate, porque es considerado un asunto de los hombres y del ámbito público. Lo anterior está estrechamente relacionado con lo que Stavenhagen (1999) expresa acerca de los derechos, el positivo y el consuetudinario, cuando estos entran en conflicto por una legislación con normas tradicionales y legales. También se encuentra explícito en la constitución en los artículos 5, 89 y 180, donde se reconoce el derecho de los pueblos indígenas de la Costa Atlántica de Nicaragua a preservar, desarrollar y tener sus propias formas de organización social, el derecho a la libre elección de sus autoridades y administrar sus asuntos locales conforme a sus tradiciones", lo anterior forma parte del sistema consuetudinario, basado en sus costumbres y tradiciones, de los pueblos indígenas de la Costa Atlántica de Nicaragua para administrar sus asuntos internos o locales y sus normas de convivencia vinculantes dentro de sus comunidades. Por otro lado, los colonos que han invadido el territorio de los indígenas de Sikilta, poseen títulos otorgados a través de escrituras públicas, documentos legalizados por abogados y a través de escrituras públicas firmados por jueces.

\section{Papel que han jugado las instituciones Gubernamentales y no Gubernamentales en el conflicto territorial}

Las principales instituciones o entidades involucradas en la solución de conflictos de tierras en el ámbito municipal y regional son el Consejo Regional Autónomo (CRA), el Gobierno Regional Autónomo (GRA) y la Oficina de Titulación Rural (OTR). Aunque por mandato de la Ley de Autonomía, al Consejo Regional Autónomo le corresponde resolver las disputas de límites dentro de las distintas comunidades de su región.

Es importante precisar que la negligencia gubernamental en el trámite de saneamiento ha acarreado problemas para las comunidades indígenas, como por ejemplo que la presencia de un colono al interior de un resguardo ha generado la llegada de nuevos colonos que van expandiendo sus mejoras hacia el resguardo, con lo cual el problema que no se soluciona a tiempo se agrava cada vez más. Por su parte, los indígenas perciben que las autoridades están a favor de los colonos, igual el Consejo Regional y los jueces por lo que no sienten que se esté dando ningún avance en la aplicación de 
la Ley 445. Los líderes de la comunidad Mayangna Sauni-Bas - Sikilta, y la sociedad civil actúan como defensores de la justicia e institucionalidad.

En entrevista al presidente del SIMSKULT ${ }^{4}$, opinó:

"El Gobierno Municipal no reconoce el derecho de la propiedad de los pueblos indígenas especialmente de la comunidad mayangna de Sikilta, porque se lava las manos y no quiere saber nada del asunto sobre el conflicto del territorio, porque muchas veces hemos solicitado el saneamiento del territorio de Sikilta, que significa desalojar a estos colonos que han llegado a ocupar tierras de manera ilegal sin consultar a los dueños del territorio de la comunidad y más bien avala otros conflictos, ya que por las campañas electorales ofrecen parcelas del territorio mayangna de Sikilta. MARENA del municipio de Siuna ha desempeñado un papel muy importante para asesorar en los temas de demarcación. Desde 1999 ha promovido las actividades en las coordinaciones de autoridades municipales y territoriales: llamado patrullaje, y la comisión interinstitucional. El objetivo principal de MARENA es dirigir la misión para evitar daños ambientales del territorio Mayangna Sauni-Bas y promover asesorías técnicas que vayan a propiciar las gestiones de desarrollo para la comunidad. De acuerdo tanto a nivel socioeconómico como ambiental de proyecto de la comunidad, además formaron dieciocho (18) guardabosques voluntarios de la comunidad mayangna de Sikilta" (Entrevista a Netan Mordy, Presidente SIMSKULT: 2008).

Los comunitarios de Sikilta, han realizado varias gestiones ante el Gobierno Municipal, Rgional y Central para lograr solucionar este problema. El Consejo Regional, ha aprobado resoluciones sobre los límites territoriales, en la que ordena al coordinador del gobierno regional a reubicar a los mestizos que ocupan de manera ilegal esta área. Ante el Gobierno Municipal, nos hemos personado gestionando sus buenos oficios a fin de que se solucione el problema. Esto ha creado comisiones conformads por miembros del Ejército de Nicaragua con presencia en Siuna, Policía Nacional, el MARENA - SETAB ${ }^{5}$, alcalde auxiliar de Kupahwas, concejales municipales, defensa civil y la Unidad de Gestión Ambiental de la alcaldía. Han sido muchas las veces que hemos gestionado ante las autoridades regionales, municipales y nacionales como la Procuraduría Ambiental donde hemos expuesto nuestra preocupación por el acelerado daño ecológico ocasionado por los despales. El pasado mes de mayo, enviamos carta al presidente de la CONADETI, solicitando la pronta titulación, ya que según los requisitos que se deben cumplir para tal fin, han sido cumplidos en referencia al

\footnotetext{
4 Asociación para el Desarrollo Comunal de Sikilta.

5 Ministerio del Ambiente y los Recursos Naturales y Secretaría Técnica de BOSAWAS.
} 
proceso que contiene cinco etapas. Lo anterior lo deja bien claro la ley 445 , sobre el régimen de propiedad comunal, refiriendo la participación de las autoridades comunales, territoriales con representación legal, las autoridades municipales, regionales y gobierno central. Sin embargo, el caso de Sikilta aún no ha sido resuelto.

\section{Conclusiones}

El desplazamiento de familias mestizas en el sector Occidente y Norte de Nicaragua, en busca de una tierra fértil y que solamente los pueblos indígenas poseen en relación a la zona de los colonos que es un desierto degradado sin producción, son las causas de los conflictos por tierra. A causa de esto, se pone en peligro de extinción, la Cosmovisión de los Pueblos Indígenas, su cultura y su administración de la tierra comunal que ancestralmente han conservado y protegido. Los suelos están degradados, los ríos han bajado su nivel que ancestralmente han mantenido. La actividad de la caza, cada vez se alejan a las profundidades del bosque para poder obtener carne de animales silvestres. Los indígenas de Sikilta conocen las leyes y normas que rigen la administración de los recursos naturales; sin embargo, no han podido resolver el conflicto. Las organizaciones gubernamentales y no gubernamentales que están relacionadas al tema, no han trascendido en ayuda a los comunitarios de Sikilta para resolver sus problemas. Se considera que no ha habido voluntad política de las autoridades regionales y municipales para ponerle fin al conflicto.

\section{Literatura citada}

Argeñal Corea, Mario (2003). Plan General de Manejo Forestal de la comunidad indígena mayangna de Sikilta, Managua, Nicaragua.

Bradford, David (2002). Ecología del medio ambiente en la Costa Caribe de Nicaragua. Centro de investigación y documentación de la Costa Atlántica (CIDCAUCA).1era. edición. Managua- Nicaragua.

Hurtado de Mendoza, Luís (1979), Plan de Manejo Territorial de Sikilta, Nicaragua.

Guardián Galio, Kauffman M (2005). ¿Minorías o pueblos indígenas y afrodescendientes en Nicaragua? Autonomía, Estado multiétnico y desarrollo humano. Reflexiones presentadas en el taller regional América Central Instituto Austriaco para América Latina (LAI), Viena; Instituto de Estudios Interdisciplinarios (IEI); Fundación "Casa de los Tres Mundos", Granada, Nicaragua. 
La Asamblea Nacional (1987). Estatuto de la Autonomía de las Regiones de la Costa Atlántica de Nicaragua, Ley No. 28.

López Bárcenas Francisco, (s/f). Distintas Concepciones de Pueblos Indígenas como sujetos de derecho colectivo.- Instituto Nacional Indigenista.- Serie Política Indigenista No. 6 México.

Nicaragua anteproyecto de la Ley de régimen de propiedad comunal de los pueblos indígenas y comunidades étnicas de las Regiones Autónomas de la Costa Atlántica (2003).

Asamblea Nacional de Nicaragua (2003). Constitución Política de la República de Nicaragua.

Ley de Municipios y sus reglamentos, República de Nicaragua, Ley No. 40 (1997).

Asamblea Nacional de Nicaragua (2006). Ley de Delitos Ambientales y contra el Medio Ambiente y los Recursos Naturales. Ley 559.Managua

Convenio, 169 (1989). Derechos de los pueblos indígenas y tribales en países independientes, Managua, Nicaragua.

Pianol Marcel y Ripert Georges, (1997). Derecho Civil, Volumen III, p.48 Clásicos del Derecho, Edit. Harla México.

Silva Edwin (1967). Derechos Humanos Historia de Fundamentos y textos. Nicaragua.

Salgado N, Duarte L. (2002). Análisis del conflicto sobre tenencia de la tierra de la comunidad mayangna de Sikilta. Siuna-RAAN.

Sánchez, C. (1996). La conformación étnico-nacional en Nicaragua. Instituto Nacional de Antropología e Historia. México.

Stavenhagen, R. (s/f). El derecho de sobrevivencia: la lucha de los pueblos indígenas en América Latina contra el racismo y la discriminación. Instituto Interamericano de Derechos Humanos Banco Interamericano de Desarrollo.

URACCAN (2001). Visión de nación multiétnica. Fortaleciendo la Visión de Nación multiétnica desde las Regiones Autónomas y Pueblos Indígenas de Nicaragua. 